Regular article

\title{
Infrared thermography for wood density estimation
}

\author{
Gamaliel López*, Luis-Alfonso Basterra, Luis Acuña \\ Research Group of Timber Structures and Wood Technology, Universidad de Valladolid, Avenida de Salamanca, 18, 47014 Valladolid, Spain
}

\section{H I G H L I G H T S}

- One simple procedure to estimate wood density was carried out.

- The numerous parameters involving the heat conduction process have been cut down.

- Relationship between density and variation of temperature is statistically manifest.

- IRT was used to monitor the evolution of the temperature over time.

\section{A R T I C L E I N F O}

\section{Article history:}

Received 9 November 2017

Revised 9 January 2018

Accepted 11 January 2018

Available online 12 January 2018

\section{Keywords:}

Timber structures

Non-destructive testing

Infrared thermography

Estimation

Density

Rehabilitation

\begin{abstract}
A B S T R A C T
Infrared thermography (IRT) is becoming a commonly used technique to non-destructively inspect and evaluate wood structures. Based on the radiation emitted by all objects, this technique enables the remote visualization of the surface temperature without making contact using a thermographic device. The process of transforming radiant energy into temperature depends on many parameters, and interpreting the results is usually complicated. However, some works have analyzed the operation of IRT and expanded its applications, as found in the latest literature.

This work analyzes the effect of density on the thermodynamic behavior of timber to be determined by IRT. The cooling of various wood samples has been registered, and a statistical procedure that enables one to quantitatively estimate the density of timber has been designed. This procedure represents a new method to physically characterize this material.
\end{abstract}

(c) 2018 Elsevier B.V. All rights reserved.

\section{Introduction}

In the inspection, diagnosis and evaluation of timber structures, density is one of the most significant physical characteristics to determine its state of preservation, quality and reliability as a structural element. In fact, density has long been the main criteria of wood selection to build timber structures. The European Standard EN 338:2010 [1] defines density as one of three main parameters of timber classification and associates its value with resistance and rigidity properties.

Instead of taking samples, certain non-destructive techniques are frequently used to estimate the density in the inspection of timber structures, such as the resistance and depth of penetration [2], screw withdrawal resistance [3], microwave scanning [4], ultrasonic velocity [5] and densitometry using X-rays or gamma rays [6,7]. However, some techniques require contact with the sample [2-5] and result in poor outcomes [3-5], and others are difficult to apply in this field [6,7]. One of the latest non-destructive

\footnotetext{
* Corresponding author.

E-mail address: gama@arq.uva.es (G. López).
}

techniques for this purpose, which produces promising results, is infrared thermography (IRT) [8].

IRT is a remote and non-contact method to visualize the surface temperature of analyzed objects based on the emitted invisible infrared radiation. The process of transforming the radiant energy into temperature depends on many parameters and interpreting the results is commonly complicated. In fact, its current use to evaluate timber structures is qualitative and practically limited to the detection of high humidity content [9], concealed wood [10,11] and significantly deteriorated areas $[12,13]$. However, some works have related density to the variation in surface temperature $[8,14]$.

Because of this relationship between density and the temperature variation, this work continues exploring the possibility of reliably estimating the density of timber using IRT. The purpose of this study is to design an easy procedure to quantitatively estimate the density of timber, simplify the heat transfer process and provide a new, truly nondestructive method to physically characterize wood.

\section{Theory}

The heat conduction phenomenon is a physical process governed by a notably complex differential equation with numerous 
parameters [15]. Specifically, in anisotropic bodies such as wood, the equation of heat transfer is as follows:

$\frac{\partial}{\partial x}\left(\lambda_{x} \frac{\partial T}{\partial x}\right)+\frac{\partial}{\partial y}\left(\lambda_{y} \frac{\partial T}{\partial y}\right)+\frac{\partial}{\partial z}\left(\lambda_{z} \frac{\partial T}{\partial z}\right)=\rho \cdot C_{e} \frac{\partial T}{\partial t}$

where $\lambda$ is the conductivity, $T$ is the absolute temperature, $\rho$ is the density, $C_{e}$ is the heat capacity, and $t$ is the time. Thus, the thermal behavior depends on both boundary conditions and body physical properties. In fact, the important parameter is the temperature variation in time, quantity and velocity, but not the absolute temperature.

Despite the complexity of the process, it has been experimentally and theoretically demonstrated that during the regular thermal regime of the heating or cooling of an object, the speed of temperature variation over time also depends on the dimension and geometry of the object and its physical properties. In this phase, the law of the temperature variation over time is common to all types of bodies and takes the following universal and exponential form [16]:

$\vartheta=C e^{-m \cdot t}$

where $\vartheta$ is the excess temperature, $t$ is time, $C$ is a constant, and $m$ is the rate of heating or cooling. The value of $m$ is constant, does not depend on location or time and determines the speed at which a body heats or cools.

\section{Materials and experimental methods}

\subsection{Instruments}

A thermaCAM B2 (FLIR Systems) infrared camera was used. This camera features a detector, which consists of an uncooled microbolometer with focal plane arrays (FPA) of $160 \times 120$-pixel resolution, and it operates in the spectral range of $7.5-13 \mu \mathrm{m}$. The thermograms were analyzed using the FLIR QuickReport 1.2 software program, and temperature data were processed using Statgraphics Centurion XV and Maple 13.00. The thermal conditioning of the test pieces was performed in an IBERTEST ES-6 furnace, and hygrothermic monitoring was obtained using a TESTO 635-2 multifunction measurement instrument.

\subsection{Specimens}

Seven different species of sawed hardwood and one laminated particle board were selected to obtain various density values. The samples were prepared to have dimensions of approximately $20 \times 30 \times 2 \mathrm{~cm}$. The density of the samples was $507.42-1060.50$ $\mathrm{kg} / \mathrm{m}^{3}$. Table 1 indicates the species of wood tested and their physical characteristics at a humidity content of approximately $6.0 \%$; the density of each specimen was obtained according to Norm EN 384:2010 [17].

\subsection{Experimental method}

The samples were heated to a temperature of $60{ }^{\circ} \mathrm{C}$ in a furnace for $72 \mathrm{~h}$. The relative humidity of the container was maintained at approximately $6.0 \%$ humidity in the samples. Then, the samples were cooled to ambient temperature $\left(25^{\circ} \mathrm{C}\right)$ for $1 \mathrm{~h}$, and the temperature of the samples at minutes $1,5,10,20,30,45$ and 60 was recorded.

Before collecting the thermograms, the temperature and ambient humidity were noted, and the incident radiation where the samples were located was measured; these parameters may affect the temperature calculation. The camera was placed and stabilized at $40 \mathrm{~cm}$ from the object during the entire process for all samples. The temperature was averaged over a surface of approximately $90 \mathrm{~cm}^{2}$ to reduce all possible surface effects of the samples. The emissivity considered for the temperature calculation was 0.90 in all cases [18].

\section{Results and discussion}

The initial hygrothermic conditions of the laboratory and samples are shown in Table 2. The temperature during the cooling process was recorded in seven thermograms for each sample (Fig. 1).

Table 1

Wood species and physical characteristics of analyzed samples.

\begin{tabular}{|c|c|c|c|c|c|c|c|}
\hline & Samples & Base $[\mathrm{cm}]$ & Height $[\mathrm{cm}]$ & Thickness [cm] & Weight $[g]$ & Density $\left[\mathrm{kg} / \mathrm{m}^{3}\right]$ & $\begin{array}{l}6.0 \% \\
\text { Form factor }\end{array}$ \\
\hline 1. & Pine & 19.60 & 30.50 & 1.80 & 546.00 & 507.42 & 0.5556 \\
\hline 2. & Moabi & 19.90 & 30.55 & 1.80 & 607.50 & 555.15 & 0.5556 \\
\hline 3. & Beech & 19.50 & 30.50 & 1.80 & 664.20 & 620.43 & 0.5556 \\
\hline 4. & Particle b. & 19.20 & 30.55 & 1.85 & 706.70 & 651.25 & 0.5405 \\
\hline 5. & Cherry & 19.70 & 30.60 & 1.75 & 824.40 & 781.47 & 0.5714 \\
\hline 6. & Sapele & 19.45 & 30.55 & 1.75 & 819.80 & 788.39 & 0.5714 \\
\hline 7. & Oak & 19.15 & 30.60 & 1.85 & 996.80 & 919.45 & 0.5405 \\
\hline 8. & Ipe & 18.50 & 30.50 & 1.80 & 1077.10 & 1060.50 & 0.5556 \\
\hline
\end{tabular}

Table 2

Initial hygrothermic conditions of the laboratory and the samples.

\begin{tabular}{|c|c|c|c|c|c|c|c|}
\hline & & \multicolumn{3}{|c|}{ Environmental conditions } & \multicolumn{3}{|c|}{ Sample conditions } \\
\hline & & $\mathrm{T}_{\text {env }}\left[{ }^{\circ} \mathrm{C}\right]$ & $\mathrm{H}_{\mathrm{env}}[\%]$ & $\mathrm{T}_{\mathrm{ref}}\left[{ }^{\circ} \mathrm{C}\right]$ & $\mathrm{T}_{\text {furnace }}\left[{ }^{\circ} \mathrm{C}\right]$ & $\mathrm{H}_{\text {furnace }}[\%]$ & $\mathrm{H}_{\text {sample }}[\%]$ \\
\hline 1. & Pine & 24.9 & 37.6 & 26.0 & 61.7 & 34.3 & 5.4 \\
\hline 2. & Moabi & 25.4 & 37.6 & 27.0 & 61.2 & 35.3 & 5.5 \\
\hline 3. & Beech & 25.6 & 37.2 & 27.5 & 61.7 & 35.2 & 5.5 \\
\hline 4. & Particle b. & 25.8 & 37.3 & 27.5 & 61.5 & 34.9 & 5.5 \\
\hline 5. & Cherry & 25.7 & 35.1 & 27.0 & 61.2 & 33.8 & 5.2 \\
\hline 6. & Sapele & 25.1 & 35.8 & 26.4 & 61.0 & 31.1 & 5.0 \\
\hline 7. & Oak & 25.9 & 34.3 & 27.5 & 61.9 & 34.5 & 5.4 \\
\hline 8. & Ipe & 26.1 & 32.1 & 28.0 & 61.3 & 34.5 & 5.4 \\
\hline
\end{tabular}




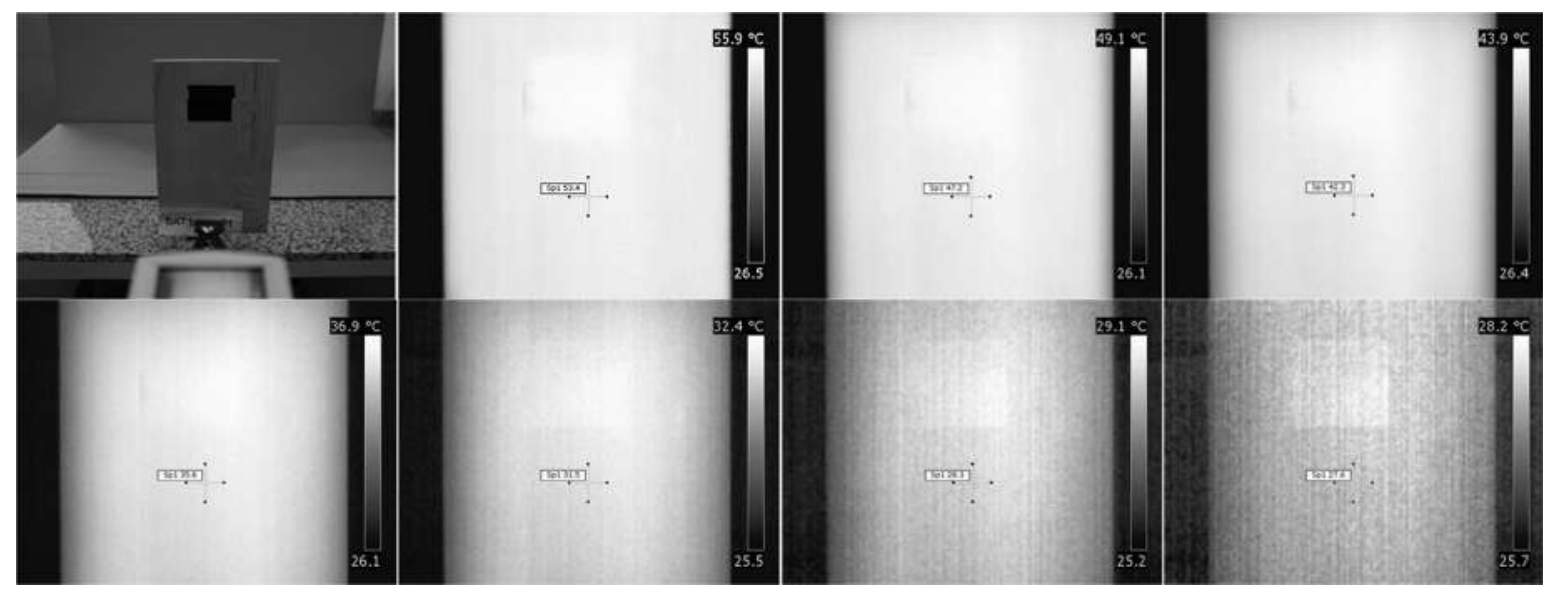

Fig. 1. Thermograms of the cooling of the beech sample over one hour.

The properly processed temperatures in those thermograms are shown in Table 3.

After the three variables in the process (density, temperature and time) were correlated (Table 3), the density of timber was presented according to the variations in absolute temperature when the seven measurements were taken (Fig. 2). The resulting regression lines of the " $y$ " axis vs. " $x$ " axis, i.e., density vs. absolute temperature, reveal a close correlation from the first five minutes of the cooling process (Table 4). Additionally, after ten minutes, the relation between the two parameters is linear and excellent, which is consistent with another work [14]. Disregarding the temperature values in the first $10 \mathrm{~min}$, the relationship between the density of timber and the variations in absolute temperature is statistically obtained: the intercept values and rate slopes at four different moments were determined to be significantly different from one another using a one-way ANOVA with $P<.001$ (Table 5).

The linear equations (Table 4 ) enabled us to estimate the density of timber according to the variations in absolute temperature when the samples were cooled from $60{ }^{\circ} \mathrm{C}$ from minute 10 at any of the four moments registered to compare the results. These equations are only valid for an 18 -mm thickness and initial heating conditions up to $60^{\circ} \mathrm{C}$ with an excess temperature of $35^{\circ} \mathrm{C}$. The initial thermal conditions equally affect all equations, particularly at the beginning of the process. However, the temperature differences among the samples after heating, which are slightly more than $1^{\circ} \mathrm{C}$, are negligible and have a minimal effect on the final result when the cooling process proceeds with time and the thermal regular regime commences.

To reduce the dependency on initial conditions, the density was related to the variations in excess temperature during the cooling process of the samples (Fig. 3). The coefficients of the regression lines slightly improve (Table 6). Disregarding the values of the first

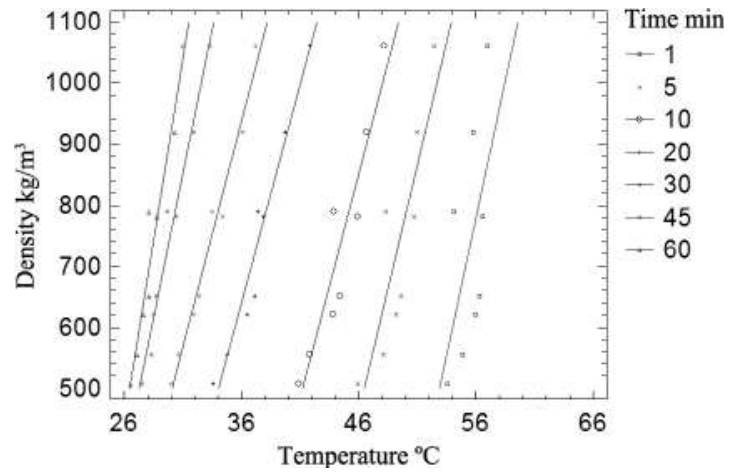

Fig. 2. Relation density-temperature over time.

Table 4

Density regression lines for temperature and correlation coefficient.

\begin{tabular}{lllll}
\hline \multicolumn{2}{l}{ Correlation between density and temperature } & & \\
\cline { 1 - 3 } Minutes & Regression line [y] & Correlation coef. & & $\mathrm{R}^{2}$ \\
\hline 1 & $-4281.86+90.3421 \mathrm{x}$ & 0.582396 & \\
5 & $-3270.96+81.1026 \mathrm{x}$ & 0.866920 & \\
10 & $-2510.93+73.0357 \mathrm{x}$ & 0.943305 & \\
20 & $-1920.27+71.1053 \mathrm{x}$ & 0.976187 & $87.1461 \%$ \\
30 & $-1705.75+73.3937 \mathrm{x}$ & 0.988755 & \\
45 & $-2066.04+94.0510 \mathrm{x}$ & 0.987319 & \\
60 & $-2652.23+119.1290 \mathrm{x}$ & 0.973315 & $97.3909 \%$ \\
& & & $93.0599 \%$ \\
\hline
\end{tabular}

ten minutes again, the relation between the two parameters is statistically obtained: the intercept values and rate slopes were determined to be significantly different from each other by a one-way ANOVA with $P<.01$ (Table 7 ).

Table 3

Temperatures registered during the cooling process from $60^{\circ} \mathrm{C}$.

\begin{tabular}{|c|c|c|c|c|c|c|c|c|}
\hline & \multicolumn{8}{|c|}{$\begin{array}{l}\text { Samples heated to } 60^{\circ} \mathrm{C} \text { and cooled to the ambient temperature } \\
\text { Temperature measured on wood surface with emissivity } 0.90\end{array}$} \\
\hline & Pine & Moabi & Beech & Particle b. & Cherry & Sapele & Oak & Ipe \\
\hline & 507.42 & 555.15 & 620.43 & 651.25 & 781.47 & 788.39 & 919.45 & 1060.5 \\
\hline 1.00 & 53.6 & 54.9 & 56.0 & 56.3 & 56.6 & 54.1 & 55.8 & 57.0 \\
\hline 5.00 & 45.9 & 48.1 & 49.2 & 49.6 & 50.7 & 48.3 & 51.0 & 52.4 \\
\hline 10.00 & 40.9 & 41.8 & 43.8 & 44.4 & 45.9 & 43.9 & 46.7 & 48.2 \\
\hline 20.00 & 33.6 & 34.8 & 36.5 & 37.1 & 37.9 & 37.4 & 39.7 & 41.8 \\
\hline 30.00 & 30.0 & 30.6 & 31.9 & 32.4 & 34.4 & 33.5 & 36.1 & 37.2 \\
\hline 45.00 & 27.5 & 28.3 & 28.5 & 28.7 & 30.4 & 29.7 & 31.9 & 33.3 \\
\hline 60.00 & 26.5 & 27.1 & 27.6 & 28.1 & 28.8 & 28.1 & 30.3 & 31.0 \\
\hline
\end{tabular}


Table 5

ANOVA Table: differences among slopes for temperature.

\begin{tabular}{|c|c|c|c|c|c|}
\hline Source & Sum of squares & df & Mean Square & $\mathrm{F}$ & $P$ value \\
\hline Excess temperature & 243612.0 & 1 & 243612.0 & 159.26 & 0.0000 \\
\hline Intercept & 680875.0 & 3 & 226958.0 & 148.37 & 0.0000 \\
\hline Slope & 35837.5 & 3 & 11945.8 & 7.81 & 0.0008 \\
\hline Model & 960324.0 & 7 & & & \\
\hline
\end{tabular}

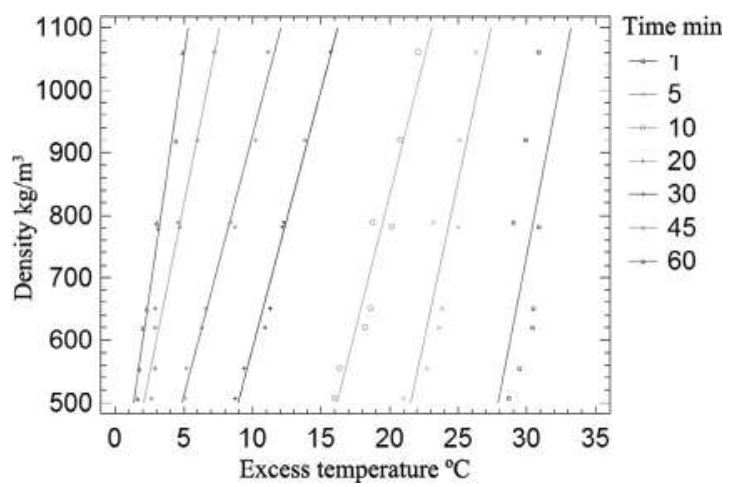

Fig. 3. Relation density-excess temperature over time.

Table 6

Density regression lines for excess temperature and correlation coefficient.

\begin{tabular}{llll}
\hline \multicolumn{4}{l}{ Correlation between density and temperature } \\
\cline { 2 - 4 } Minutes & Regression line [y] & Correlation coef. & $\mathrm{R}^{2}$ \\
\hline 1 & $-2645.28+112.7870 \mathrm{x}$ & 0.503884 & $12.9549 \%$ \\
5 & $-1715.64+102.8280 \mathrm{x}$ & 0.893469 & $76.4668 \%$ \\
10 & $-897.575+86.4637 \mathrm{x}$ & 0.960958 & $91.0680 \%$ \\
20 & $-234.276+82.2722 \mathrm{x}$ & 0.989402 & $97.5402 \%$ \\
30 & $-96.2591+83.0193$ & 0.990479 & $97.7891 \%$ \\
45 & $-275.238+108.94$ & 0.982518 & $95.9565 \%$ \\
60 & $-299.32+151.717$ & 0.989147 & $97.4813 \%$ \\
\hline
\end{tabular}

The resulting equations (Table 6) enabled us to estimate the density of timber according to the sample thickness $(18 \mathrm{~mm})$ and an excess temperature of $35^{\circ} \mathrm{C}$ regardless of the initial temperature of the samples.

Finally, to avoid a fixed initial excess temperature, the density of timber was presented according to the normalized excess temperature in relation to the excess temperature in the first minute for each sample (Fig. 4). Similar correlation coefficients were obtained (Table 8); disregarding the values of the first ten minutes, the relation between the two parameters is statistically obtained: the intercept values and rate slopes were determined to be significantly different from each other by one-way ANOVA with $P<.01$ (Table 9).

The resulting equations (Table 8 ) enabled us to estimate the density of timber according to the sample thickness $(18 \mathrm{~mm})$ and a normalized excess temperature compared to the first minute.

In the three cases, the rate slopes of the regression lines after ten minutes show that the values parabolically increase. This relation must be compared with more experimental data because the

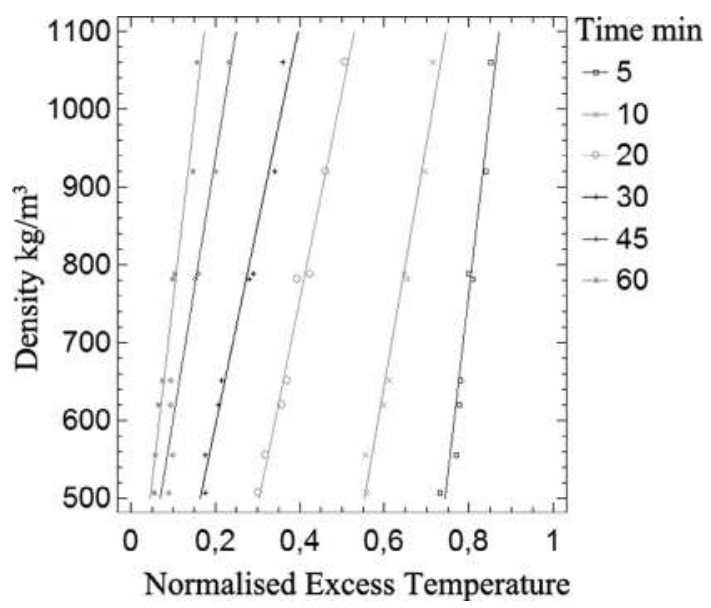

Fig. 4. Relation density-normalised temperature over time.

Table 8

Density regression lines for normalized excess temperature and correlation coefficient.

\begin{tabular}{llll}
\hline \multicolumn{4}{l}{ Correlation between density and temperature } \\
\cline { 2 - 4 } Minutes & Regression line $[\mathrm{y}]$ & Correlation coef. & $\mathrm{R}^{2}$ \\
\hline 5 & $-3004.95+4706.82 \mathrm{x}$ & 0.978494 & $95.0359 \%$ \\
10 & $-1235.45+3131.73 \mathrm{x}$ & 0.983748 & $96.2387 \%$ \\
20 & $-314.167+2674.83 \mathrm{x}$ & 0.990958 & $97.8997 \%$ \\
30 & $-73.573+2584.2 \mathrm{x}$ & 0.983768 & $96.2433 \%$ \\
45 & $-263.24+3362.0 \mathrm{x}$ & 0.976077 & $94.4847 \%$ \\
60 & $-288.419+4681.06 \mathrm{x}$ & 0.984899 & $96.5031 \%$ \\
\hline
\end{tabular}

deduction is based on only four measurements. Nonetheless, this behavior appears reasonable because the gradient of these lines progressively increases to infinity when the heat transfer ceases and the samples reach thermal equilibrium with the environment.

\section{Conclusions}

The density of wood is closely related to the speed of temperature variation in time. IRT was used to monitor the temperature evolution over time and design a procedure to quantitatively estimate the wood density.

The procedure consists of deducing equations that relate the density with the temperature during the sample-cooling process. The determination coefficient after the tenth minute is excellent, and the two parameters are linearly correlated. This procedure

Table 7

ANOVA Table: differences among slopes for excess temperature.

\begin{tabular}{|c|c|c|c|c|c|}
\hline Source & Sum of squares & df & Mean Square & $\mathrm{F}$ & $P$ value \\
\hline Excess temperature & 195741.0 & 1 & 195741.0 & 195.75 & 0.0000 \\
\hline Intercept & 728341.0 & 3 & 242780.0 & 242.79 & 0.0000 \\
\hline Slope & 48954.9 & 3 & 16318.3 & 16.32 & 0.0000 \\
\hline Model & 973037.0 & 7 & & & \\
\hline
\end{tabular}


Table 9

ANOVA Table: differences among slopes for normalized excess temperature.

\begin{tabular}{|c|c|c|c|c|c|}
\hline Source & Sum of squares & df & Mean square & $\mathrm{F}$ & $P$ value \\
\hline Norm. Excess temperature & 179618.0 & 1 & 179618.0 & 135.70 & 0.0000 \\
\hline Intercept & 741851.0 & 3 & 247284.0 & 186.82 & 0.0000 \\
\hline Slope & 43798.5 & 3 & 14599.5 & 11.03 & 0.0001 \\
\hline Model & 965268.0 & 7 & & & \\
\hline
\end{tabular}

enables one to evaluate the density of timber as often as measurements are taken after ten minutes to compare and verify the resulting values.

The validity of these equations significantly depends on the conditions of the test, sample thickness, initial temperature and initial excess temperature. In this work, three distinct families of equations were obtained for $18-\mathrm{mm}$ samples to reduce the dependency on the initial conditions and achieve greater flexibility. These equations are relatively easy to apply because they only require the measurement of the wood temperature at the corresponding times with a thermographic camera.

Research is currently being performed to increase the number of measurements in the cooling process and expand these equations for greater thickness to find a relation between the different thickness.

\section{Conflict of interest}

The authors declare that there is no conflict of interest.

\section{acknowledgement}

The present work was made possible thanks to the financial support of the Junta de Castilla y León through the grants provided for research projects at the beginning of 2006 (ref. VA006A07).

\section{References}

[1] EN 338:2009, Structural timber. Strength classes.

[2] L. Acuña, L.A. Basterra, M. Casado, G. López, G. Ramón-Cueto, E. Relea, C. Martínez, A. González, Application of resistograph to obtain the density and to differentiate wood species, Materiales de Construcción 61 (303) (2011) 451464.

[3] Z. Cai, M.O. Hunt, R.J. Ross, L.A. Soltis, Screw Withdrawal - A Means to Evaluate Densities of In-situ Wood Members, in: Proceedings of the 13th International
Symposium on Non-destructive Testing of Wood, California, USA, August 1921, 2002.

[4] N. Lundgren, O. Hagman, J. Johansson, Predicting moisture content and density distribution of Scots pine by microwave scanning of sawn timber II: Evaluation of models generated on a pixel level, J. Wood Sci. 52 (2006) 39-43.

[5] F.G.R. Oliveira, A. Sales, Relationship between density and ultrasonic velocity in Brazilian tropical woods, Bioresour. Technol. 97 (2006) 2443-2446.

[6] V. Bucur, Nondestructive characterization and imaging of wood, Springer, New York, 2003.

[7] B. Arango, L. Tamayo, Density of wood in eucalyptus clones using X-ray densitometry, J. Facul. Eng. Univ. Antioch 45 (2008) 87-99.

[8] G. López, L.A. Basterra, L. Acuña, Estimation of wood density using infrared thermography, Constr. Build. Mater. 42 (2013) 29-32.

[9] G.M. Fike, J. Abedi, S. Banerjee, Imaging the drying of surfaces by infrared thermography, Ind. Eng. Chem. Res. 43 (2004) 4178-4181.

[10] C. Plescanu, M.T. Cochior, C. Klein, A Ibarra-Castanedo, A. Bendada, X. Maldague, Localization of wood floors structure by infrared thermography, in: Proceedings of the 30th SPIE (Thermosense XXX), Orlando, USA, March 18202008.

[11] M. Spencer, J. Nychka, L. Penn, L. Boyer, L. Everlade, J. Liebertz, Applying infrared thermography for the purpose of identifying concealed wood framing member type and subsurface anomalies with intended application towards historic structures, National Center for Preservation Technology and Training USA, 2008.

[12] A. Wyckhuyse, X. Maldague, A study of wood inspection by infrared thermography, part I: Wood pole inspection by infrared thermography, Res. Nondestr. Eval. 13 (1) (2011) 1-12.

[13] A. Wyckhuyse, X. Maldague, A study of wood inspection by infrared thermography, part II: Thermography for wood defects detection, Res. Nondestr. Eval. 13 (1) (2011) 13-22.

[14] T. Tanaka, F. Divós, Wood inspection by thermography, in: Proceedings of the 12th International Symposium on Nondestructive Testing of Wood, Sopron, Hungary, September 13-15 2000.

[15] V. Vavilov, Thermal non-destructive testing: short history and state-of-art, in: Proceedings of 1 st International Conference on Quantitative Infrared Thermography (QIRT 92), 7-9 July 1992, pp. 179-194. Châtenay-Malabry, France, 1992.

[16] V. Isachenko, V. Osipova, A. Sukomel, Heat Transfer, University Press of the Pacific, USA, 2000.

[17] EN 384:2010, Structural timber. Determination of characteristic values of mechanical properties and density.

[18] G. López, L.A. Basterra, L. Acuña, Determination of the emissivity of wood for inspection by infrared thermography, J. Nondestr. Eval. 32 (2013) 172-176. 